\title{
Farmer's lung: a study of an early acute fatal case
}

\author{
D. F. BAR R OWCLIFF AND P. G. ARBLASTER \\ From the Group Laboratory, Warwick, and the Royal Hampshire County Hospital, Winchester
}

\begin{abstract}
The clinical and pathological findings in a fatal case of farmer's lung in a 17-year-old youth are described. His lungs were uncomplicated by chronic disease, and his first exposure to mouldy hay probably occurred only weeks before his death. As this was an acute attack, whose duration could be measured in days, the changes seen are probably the earliest to be recorded, and the probable nature of the sensitivity reaction can be deduced. The pathological process is seen to be an acute centrilobular bronchopneumonia of a special type and is associated with an obstructive bronchiolitis. There is a focal interstitial pneumonia with much proliferation of alveolar epithelium, and there is a necrotic exudate in which neutrophils and eosinophils are seen along with mononuclears, some lymphocytes, and plasma cells. The alveolar spaces are in many cases obscured, but others contain a haemorrhagic fluid. Alveolar capillaries show an acute vasculitis, with platelet and fibrin deposition, and with acute neutrophil infiltration. Serological and mycological data are included. Precipitins to mouldy hay and to Thermopolyspora polyspora were found in the serum. In dusts collected from his habitat $T$. polyspora was found. We think the bronchiolitis explains the severe dyspnoea, and the vasculitis accounts for the malaise, fever, and haemoptysis. The histological findings are compared with accounts of experimentally produced Arthus reactions and tuberculin reactions, and we give our reasons for believing the fundamental lesion to be an Arthus reaction.
\end{abstract}

There is good evidence that farmer's lung is the result of a hypersensitivity reaction caused by antigens found in mouldy hay or cereals (Pepys and Jenkins, 1965). In a typical case of several years' duration the histological picture of granulomata, with scarring and distortion of both bronchioles and lung parenchyma, gives no clue as to the aetiology of the condition. Nor does material obtained by lung biopsy from cases of shorter duration, which often show giant-cell granulomata (Totten, Reid, Davis, and Moran, 1958 ; Seal, Thomas, and Griffiths, 1963). No descriptions of patients who have died in the first attack of the disease have been published, although the account by Höer, Horbach, and Schweisfurth (1964) of the death of a 15-year-old boy after a three-week illness said to have been caused by Aspergillus fumigatus could well have been of an acute attack of farmer's lung.

\section{HISTORY}

The deceased schoolboy was a 17-year-old farmer's son, who first complained of symptoms in September 1964. Previously in perfect health, he had been awarded the victor ludorum in his school sports earlier that summer. He had spent the summer helping his father, and his first $\stackrel{\bar{\partial}}{\exists}$ known exposure to mouldy hay occurred only weeks before his death.

When first seen at the beginning of October 1964 he admitted to having felt tired and to looking ill for about eight weeks. For one week he had experienced a constricting pain across the $\dot{0}$ chest, had sweated at night, and had coughed up some faintly blood-stained sputum. Three days $\delta$ later he was pyrexial and was dyspnoeic but was $₹$ still ambulant. He looked anxious and complained 윽 of a headache. Crepitations were heard at the base of the right lung and a course of penicillin was? started. The following day his condition had worsened, he had vomited once, crepitations were $ᄋ$ present throughout the chest, and he was admit- $N$ ted to hospital.

Examination showed an anxious boy, who was cyanosed and dyspnoeic at rest. The temperature was $100 \cdot 2^{\circ} \mathrm{F}$., pulse rate $120 /$ minute, and res- $\frac{\complement}{\Phi}$ piration rate $40 /$ minute. Chest radiography $\stackrel{\odot}{+}$ showed miliary opacities throughout the lung 0 fields which were most marked in the lower and mid-zones. Anti-tuberculosis therapy was started. $\stackrel{\mathbb{D}}{\circ}$

Twenty-four hours after admission his condi- $\overrightarrow{\mathbb{D}}$ tion had deteriorated further. Laboratory results $\sigma$ available at that time included: Westergren 
E.S.R. $90 \mathrm{~mm}$. in one hour; total W.B.C. $27,000 /$ c.mm. (neutrophils 77\%); pH 7.4; $\mathrm{PcO}_{2} 53 \mathrm{~mm}$. $\mathrm{Hg}$; base excess $+4.5 \mathrm{mEq} / \mathrm{l}$. Serum $\gamma$-globulin was not increased. No acid-fast bacilli were found in the sputum, which yielded a pure growth of Candida albicans on culture. Broncho-pulmonary mycosis and farmer's lung were considered as possible diagnoses. He was given $100 \mathrm{mg}$. hydrocortisone and $5 \mathrm{mg}$. amphotericin intravenously. The pulse rate remained high at $120-150 /$ minute and the respiration rate at $40-50 /$ minute; the blood pressure was $120 / 60 \mathrm{~mm}$. $\mathrm{Hg}$. As the respiratory load was considered intolerable a tracheostomy was performed, but he died six hours later, two days after admission to hospital and about 10-12 days after the onset of clinical disability.

\section{NECROPSY}

The lungs showed a mild degree of overdistension. The pleural surfaces were not remarkable. Small effusions of clear fluid were seen in each pleural cavity.

Miliary nodules were distributed throughout the cut surface of each lobe. They were firm, discrete, and grey-centred and were ringed with a zone of haemorrhagic consolidation which in places extended to produce a segmental collapse. Although this collapse was more prominent in the lower than in the upper lobes, there was probably no significant difference in the distribution of the nodules between the upper and lower lobes, or between the central and the peripheral part of any lobe. The intervening parenchyma showed a little compensatory emphysema (Fig. 1).

Hilar lymph nodes were enlarged and soft, with an unremarkable grey cut surface. The large- and medium-sized bronchi contained small quantities of mucoid material. Apart from some hyperaemia their mucous membranes were not remarkable. Culture yielded a pure growth of Candida albicans.

The remainder of the organs showed only deep passive congestion.

HISTOLOGICAL EXAMINATION OF THE LUNG The typical nodule was a discrete, fairly compact, centrilobular, cellular mass with a well-defined margin (Fig. 2). Nodules were separated either by aerated alveoli or by a lung parenchyma having thickened septa infiltrated with mononuclear cells, with or without an exudate in the alveolar spaces containing scanty mononuclears and a serous or haemorrhagic fluid. The description of the microscopical features of a nodule may for convenience

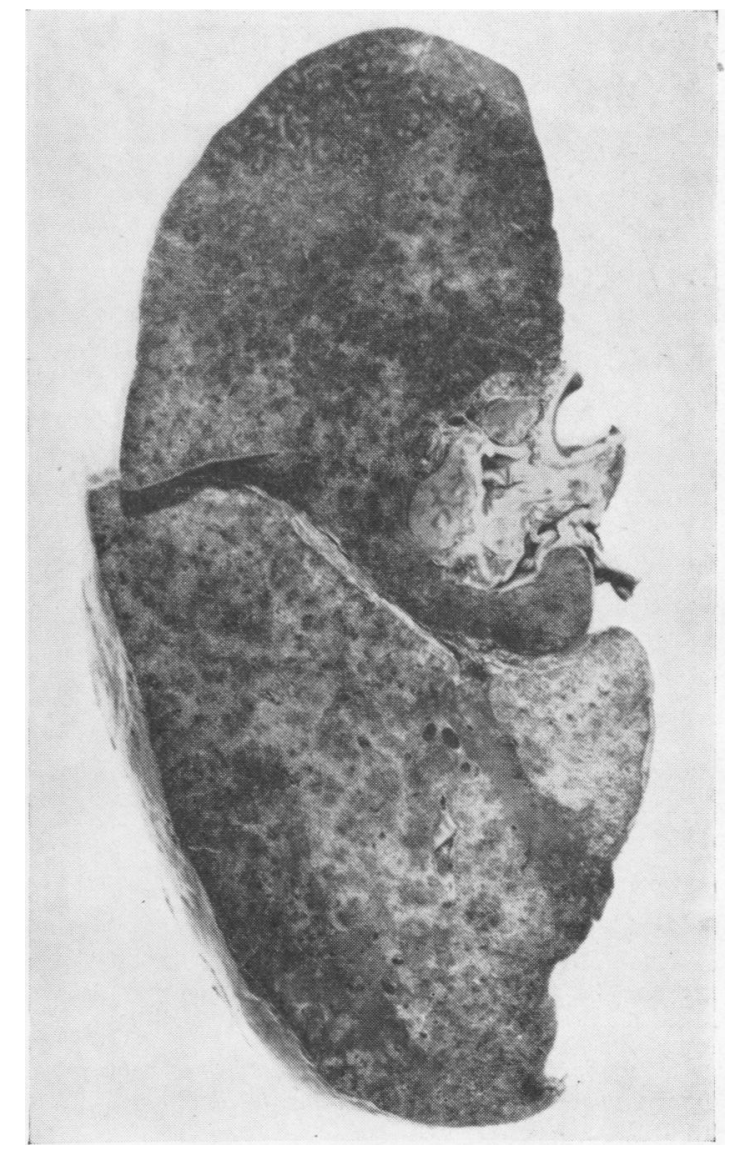

FIG. 1. Surface of left lung showing haemorrhagic foci, consolidation, and segmental collapse. $\left(\times\right.$ approx. $\left.\frac{1}{2}.\right)$

be divided into that of the alveoli, that of the smallest blood vessels, and that of the small bronchioles, but in any nodule all three affected structures were usually identified.

The affected alveoli lay in close relationship to the respiratory bronchioles, and the process could be described as a bronchopneumonia of a special type. The changes were those of an interstitial pneumonia, and several variants were seen which probably represented stages varying from a welldeveloped lesion to the very earliest change.

The well-developed nodule consisted of an almost confluent mass of plump proliferating alveolar epithelial cells with prominent groups of lymphocytes, and with a few acute inflammatory cells, neutrophils, and eosinophils (Fig. 3). Plasma cells were present but were not abundant. In sections stained for reticulin the basic alveolar structure could still be made out, at least in the 


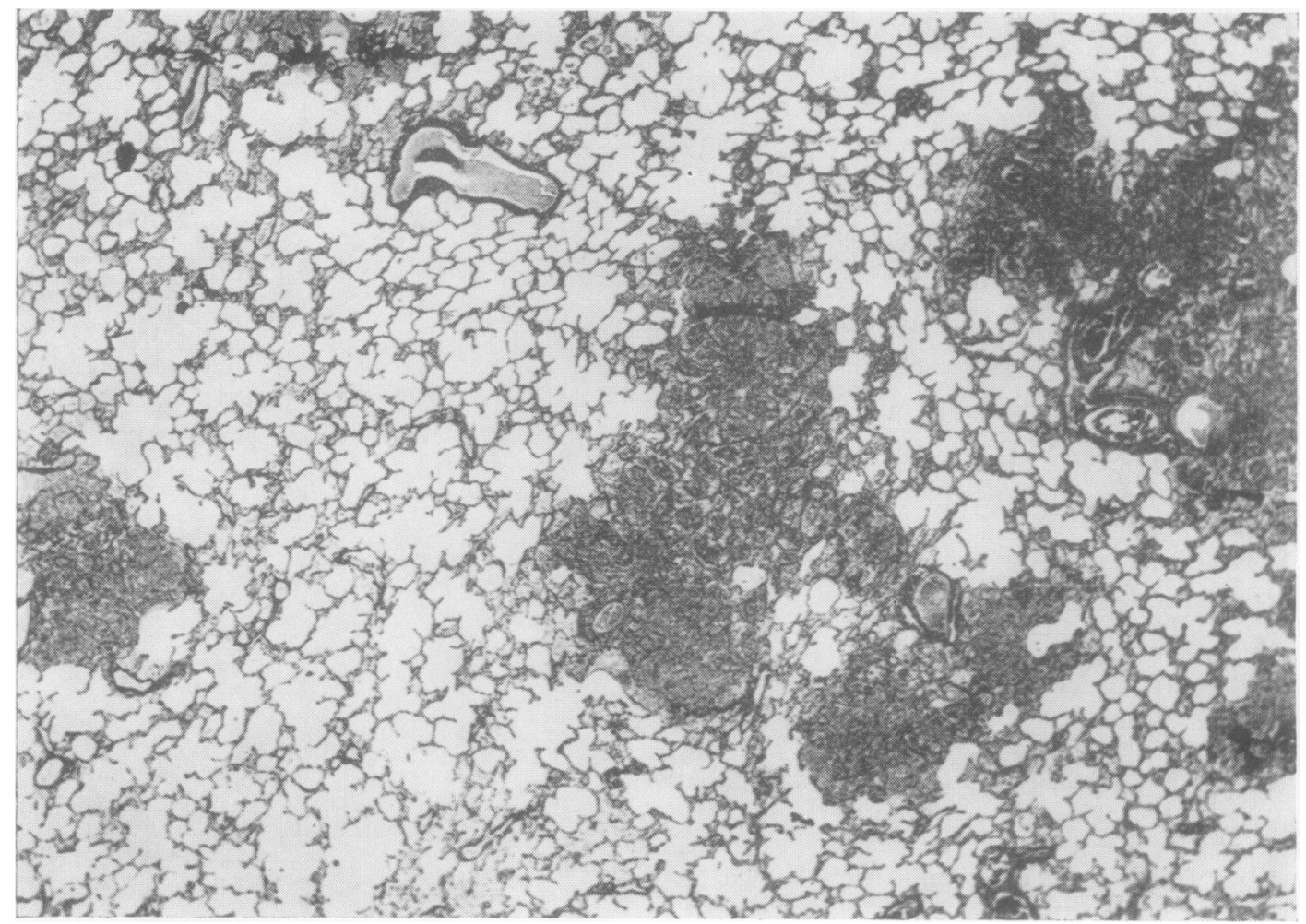

FIG. 2. Section skowing discrete nodules of centrilobular interstitial bronchopneumonia, some thickening of septa of intervening lung, and fluid in some alveolar spaces. (Silver stain $\times 30$.)

periphery of the nodule, but at its centre a dense mass of fresh reticulin obscured this pattern (Fig. 4). Very fine collagen fibres could be demonstrated. No bi-refringent material could be made out.

In the less well-developed nodules there was a proliferation of alveolar epithelium which generally obscured the alveolar spaces, and a necrotic exudate of neutrophils, eosinophils, and of large mononuclears which sometimes resembled histiocytes, sometimes appeared to be of alveolar or alveolar duct origin, but frequently were of indeterminate origin (Fig. 5). Multinucleate cells, typical of those seen in any proliferating alveolitis, were also seen (Fig. 6). In what remained of the alveolar spaces there were frequent haemorrhages or a protein-rich fluid, together with the inflammatory cells.

In the least affected lung, as at the periphery of a nodule or in the parenchyma between nodules, the alveolar pattern was undisturbed, there was thickening of alveolar walls, mono nuclear infiltration of these walls, a faintly bloodstained protein-rich exudate in the alveolar spaces, and a capillary dilatation which was on occasions? very marked.

Where the process was probably both earlies in time and most acute there was an acutes vasculitis, affecting alveolar capillaries and per haps some small arterioles. Platelet and fibrin deposition was seen, together with thromboses, $\omega$ haemorrhages, neutrophil infiltration of the affected wall, and disruption and reduplication of the wall with fibrin casts in the alveolar spacesक (Figs 5 and 7).

The only arteritis affecting larger arterioles 0 which could be identified with certainty was lowgrade and probably of a secondary nature, the? vessel being surrounded by a mass of acute or chronic inflammatory cells which derived from the surrounding pneumonia. Its adventitia waso sometimes oedematous, but its intima waso 


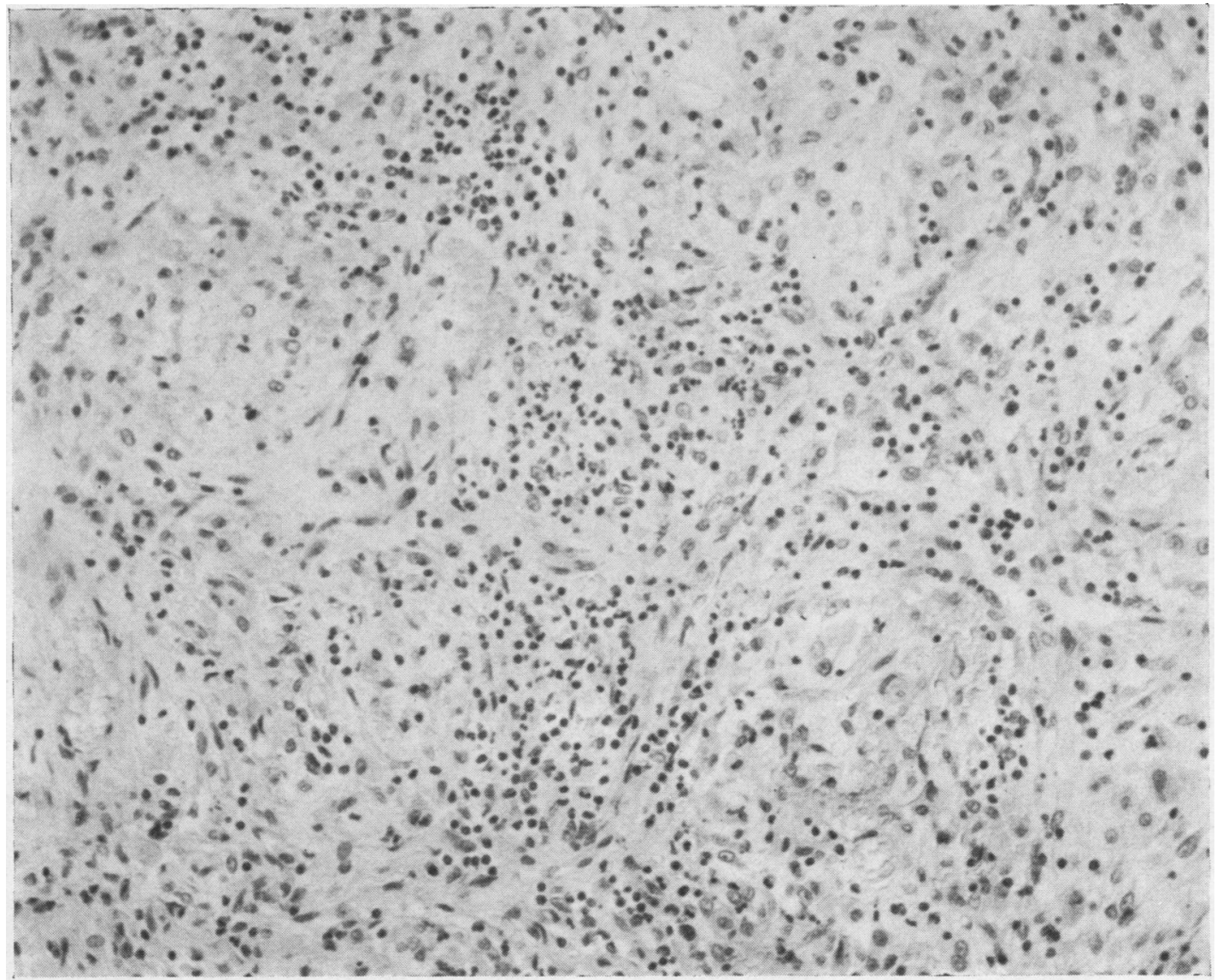

FIG. 3. Section of a well-developed nodule, showing a sheet of proliferating epithelial cells together with acute and chronic inflammatory cells. $($ H.E. $\times 200$.)

unaffected. No arteritis of a severity comparable with the vasculitis seen in the capillaries was present. The vessels in the lung tissue between the nodules showed no changes other than the capillary dilatation described.

Where a bronchiole, always a centrilobular respiratory bronchiole, was involved, a segment of its wall had frequently disintegrated and was replaced by a mass of mixed cells, fibrin, and debris, which filled, sometimes completely, the lumen of the organ, causing an obstructive bronchiolitis (Fig. 8). Some mucin was present in this necrotic exudate. Neutrophils and mononuclears were frequent, eosinophils uncommon. Multinucleate giant cells were occasionally seen within the bronchiole, some evidently formed by the mucosal margin of the break where it had attempted to regenerate, some probably originating in the epithelium of alveoli or alveolar ducts.
Except at the point it had been breached, the bronchiolar wall was relatively normal or only sparsely infiltrated with round cells, despite the very active reaction which was taking place in the adjoining tissue.

IMMUNOLOGICAL AND MYCOLOGICAL FINDINGS The serum obtained shortly before death tested by one worker showed precipitins to Aspergillus fumigatus, Micromonospora vulgaris, and Thermopolyspora glauca but not to Candida albicans or to Thermopolyspora polyspora. In another laboratory precipitin reactions with mouldy hay extracts and with $T$. polyspora were demonstrated. Culture of material obtained from the bronchi post mortem, as well as of sputum, yielded only Candida albicans. Various dusts were collected from the habitat of the deceased and were examined by Dr. I. G. Murray and Dr. P. H. 


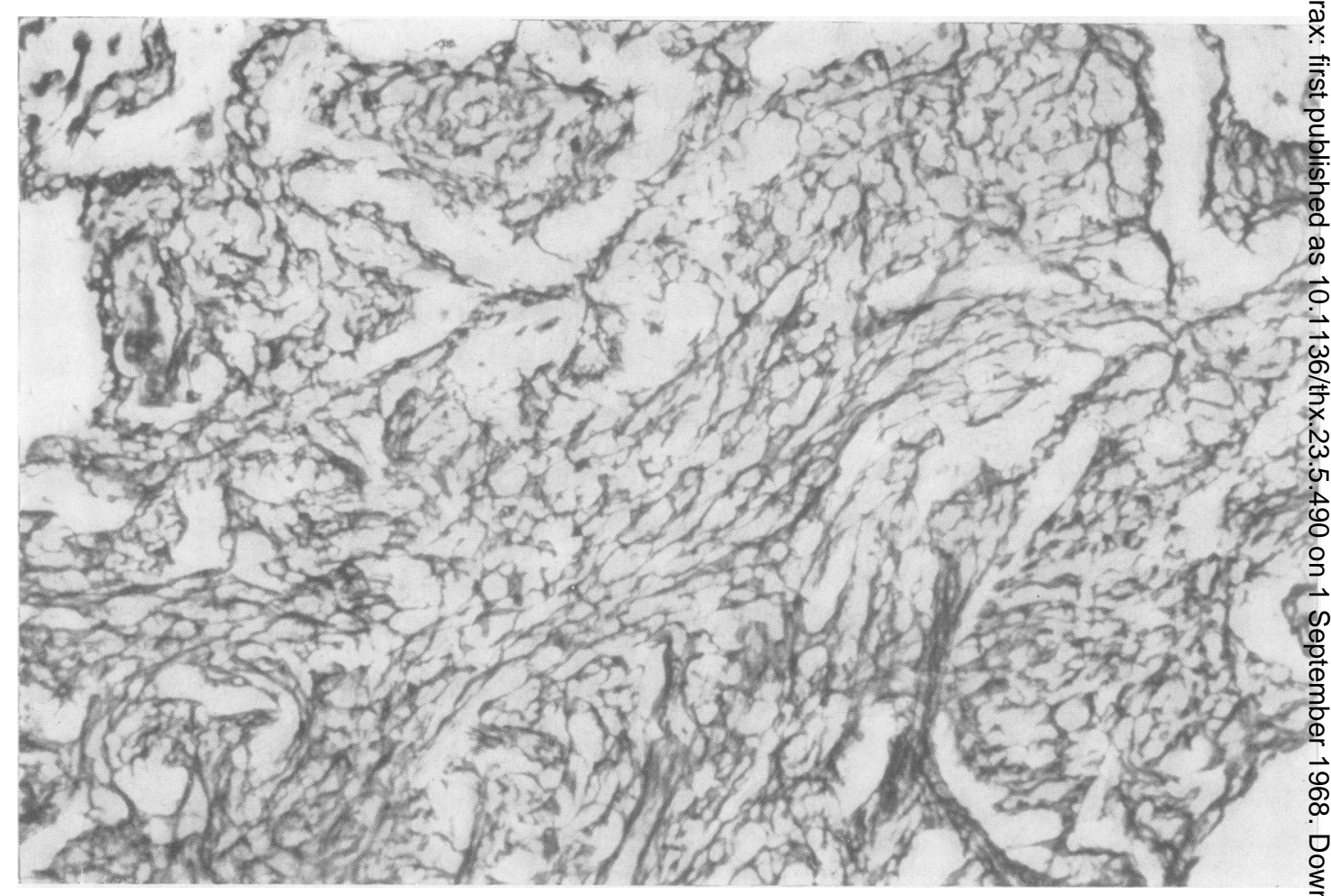

FIG. 4. Section showing fresh reticulin with alveolar pattern recognizable at periphery of nodule. (Silver stain $\times 300$.

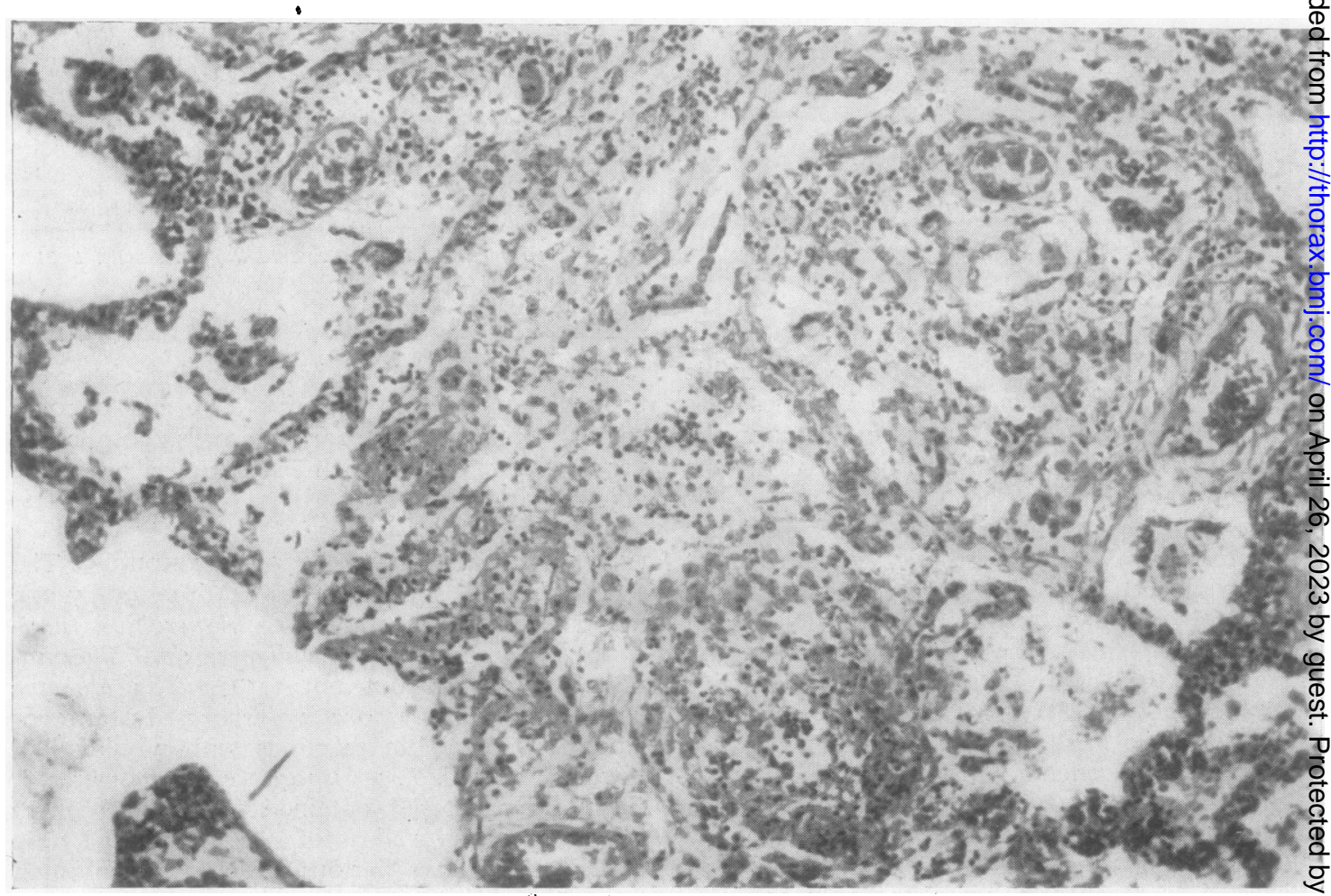

FIG. 5. Section of an early lesion showing a necrotic exudate of inflammatory cells, disruption of some alveolag capillaries, with a necrotic exudate of inflammatory cells. Some multinucleate alveolar epithelial cells. $(H . E . \times 150$. 


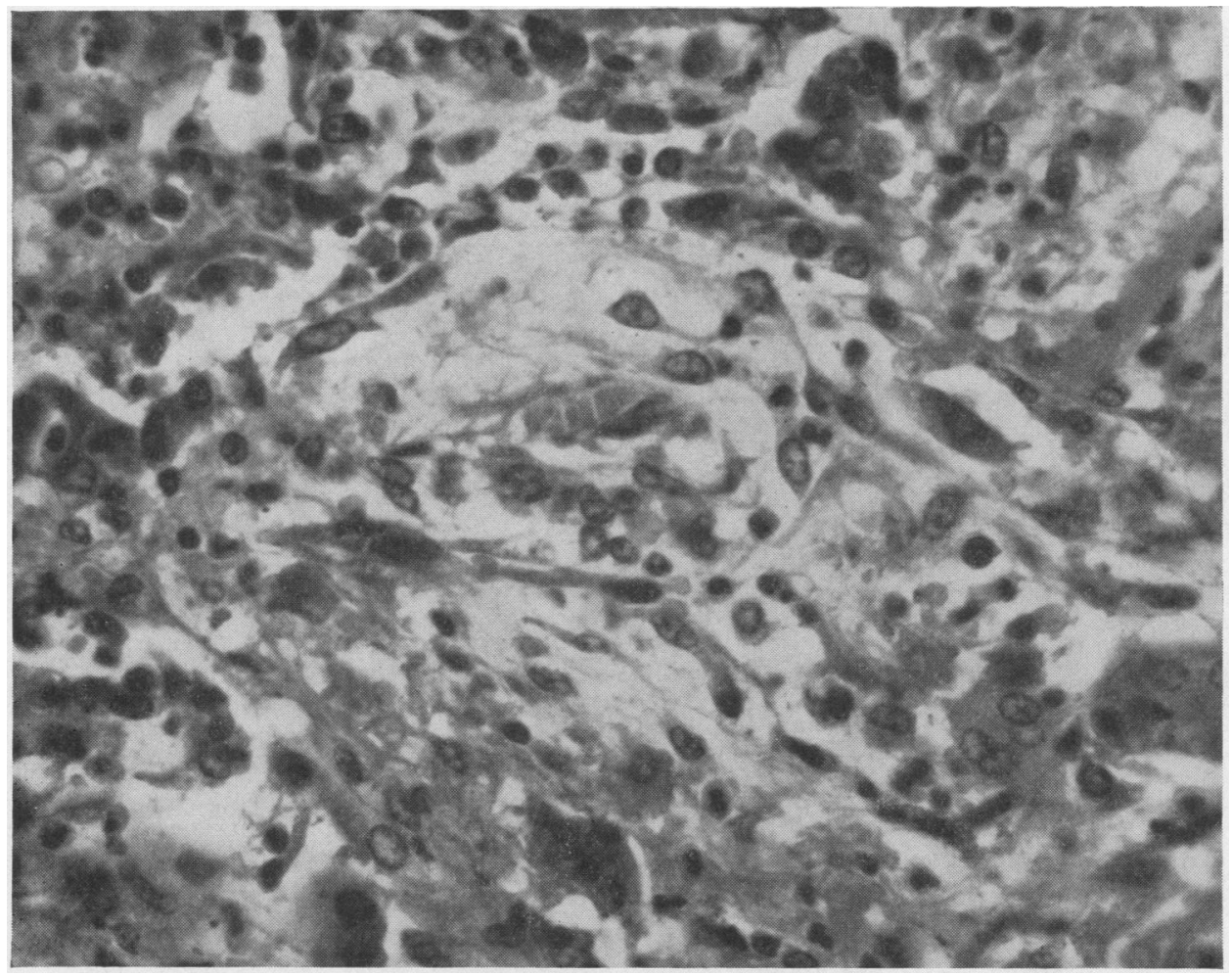

FIG. 6. High-power section of a nodule showing proliferating alveolar epithelium, large mononuclear cells, multinucleate giant cells, plasma cells, lymphocytes, polymorphs, and some haemorrhage. (H.E. $\times 450$.

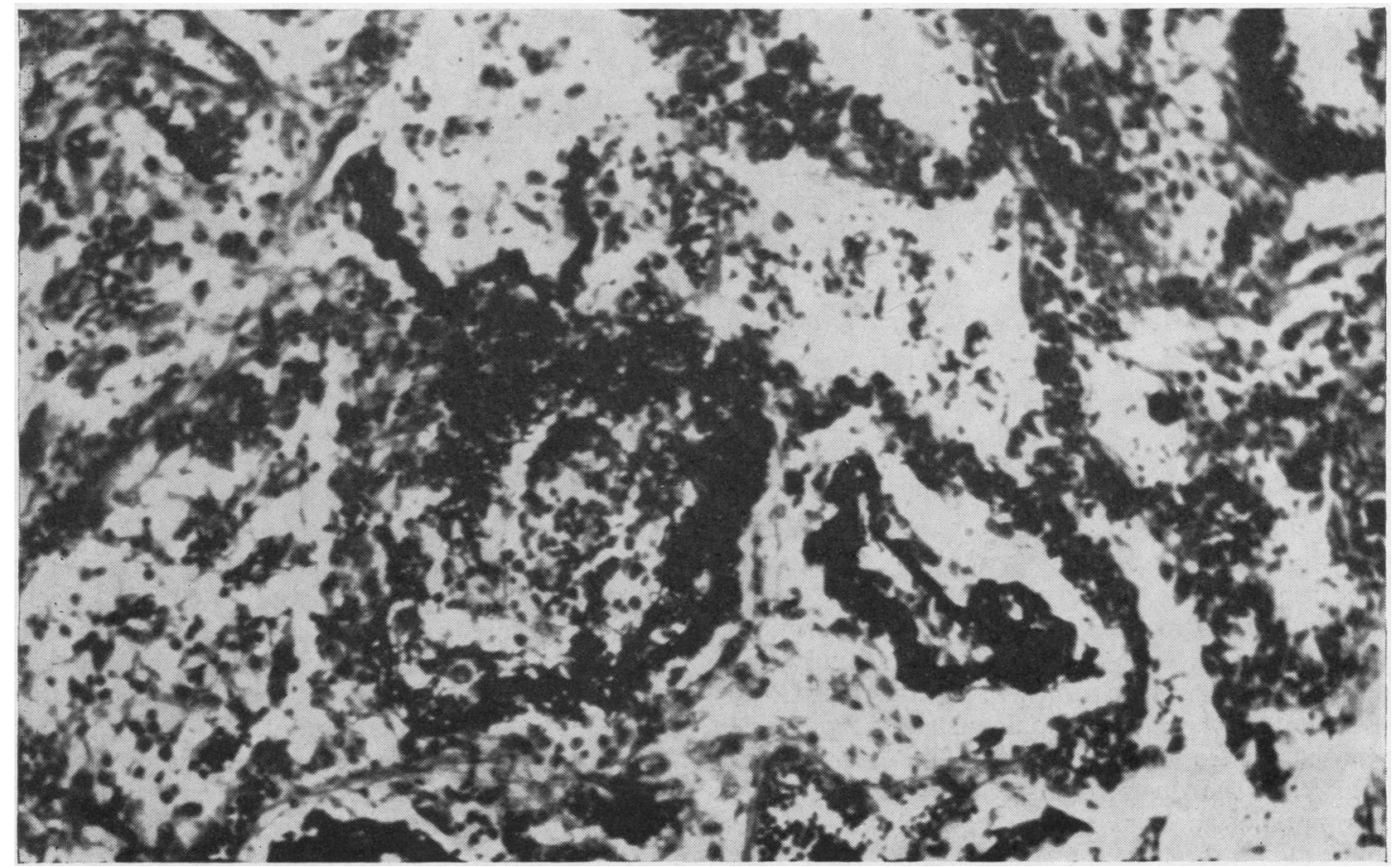

FIG. 7. The same as in Fig. 5, showing fibrin thrombi in the capillary lumen of a disrupted alveolus and fibrin exudates in alveolar spaces. (P.T.A.H. $\times 250$.) 


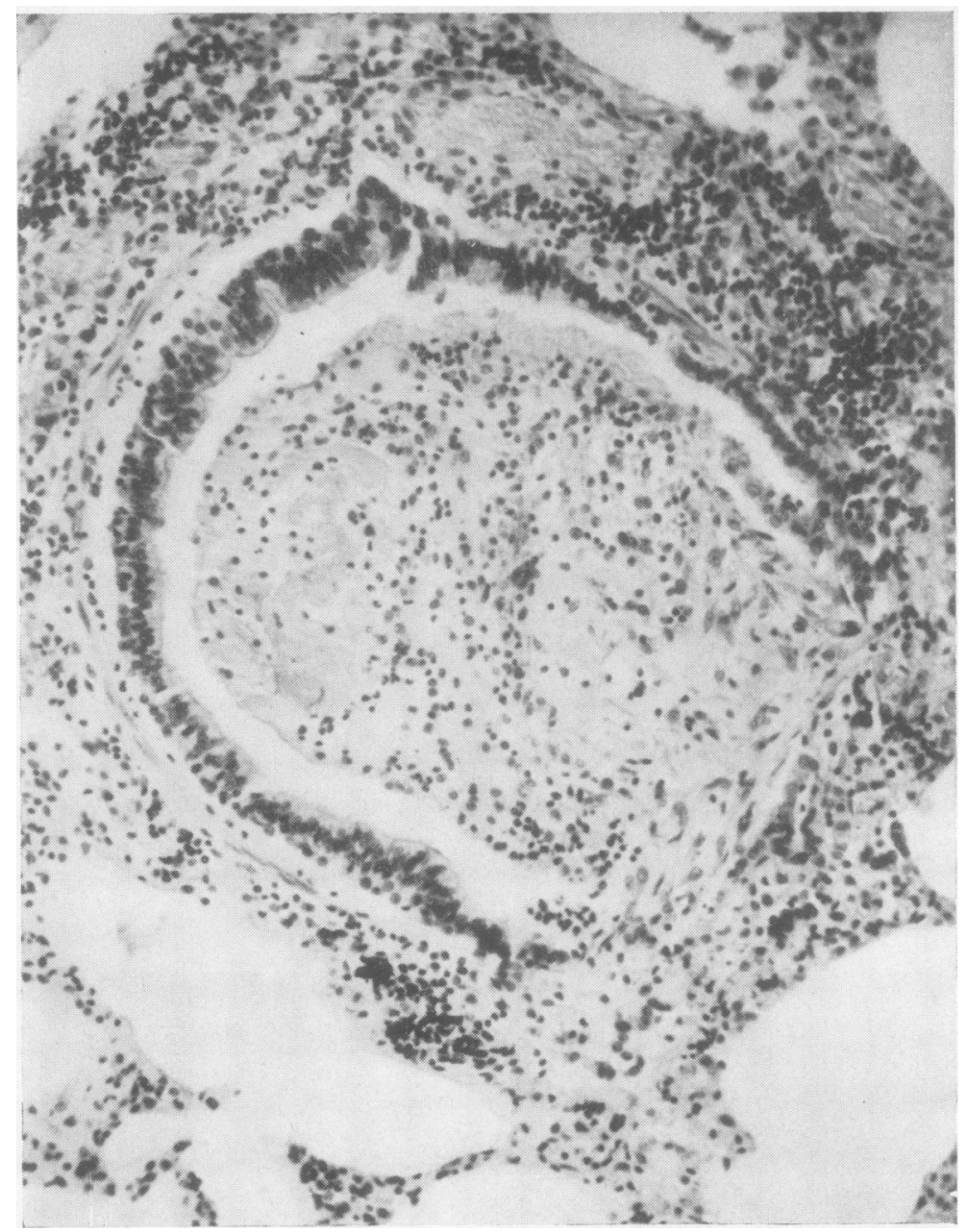

FIG. 8. Section of a respiratory bronchiole showing disintegration of a segment of its wall, from which a mass of mixed inflam- $\overrightarrow{-}$ matory cells, fibrin, and debris is invaginated to cause an obstructive bronchiolitis. The remainder of the bronchiolar wall is normal. Alveolar septa, thickened and infiltrated with mononuclears, are also shown. $\overrightarrow{0}$ (H.E. $\times 150$.

Gregory. These workers identified $T$. polyspora in the specimens but stated that this was outnumbered by $M$. vulgaris and $T$. glauca.

\section{DISCUSSION}

There can be little doubt that this boy suffered from an acute attack of farmer's lung, which was exceptional in that it caused death. The occurrence in any farm worker of an acute pulmonary disability which follows exposure to mouldy hay and which is characterized by severe dyspnoea with blood-stained sputum, associated with fever and malaise, invites this diagnosis. The isolation of fungi from the dusts of his habitat, among them thermophilic species, whose corresponding precipitating antibodies are to be found in a high proportion of cases of the disease, and the finding in the serum of the deceased of antibodies too these and to mouldy hay extract leave little doub? that the disease was farmer's lung.

This is amply confirmed by the histologica features. Several descriptions of the pathologicap changes occurring only weeks or months after an acute attack of the disease are available (Seat et al., 1963 ; Emanuel, Wenzel, Bowerman, and6 Lawton, 1964), and the changes noted in this case are fully compatible with the description by those authors of a diffuse interstitial pneumonia? obstructive bronchiolitis, and granulomatouso nodules, if allowance is made for the earlier stage at which this case was examined. Thus fibrosis a marked feature of the chronic disease and always present to some degree in those cases described as being acute, is virtually absent here but had this patient survived the abundant 
reticulin seen is indicative of the fibrosis which might have been expected.

The vasculitis which we observed differs from that described in other accounts in that it was acute and virtually restricted to capillaries, whereas that noted in the cases examined later in the disease was an endarteritis of arterioles, which may have been of a secondary nature. If the traditional classification of cases of farmer's lung into acute and chronic is maintained, in such context this present case should be described as being 'pre-acute', for having regard to his youth, to his history of only infrequent exposure, and to his short clinical history, the lesions observed in the lung must represent a very early stage in their pathological development.

PATHOGENESIS OF THE PULMONARY LESIONS The lesions do not represent a true mycosis, for no fungi or other organisms were seen in the sections of the lung, and culture yielded only Candida albicans. This fungus has been isolated from $50 \%$ of some series of farmer's lung, but the consensus of opinion expressed by Dickie and Rankin (1958) is that its presence is indicative only of exposure to a fungus-laden atmosphere, perhaps encouraged by antibiotic therapy.

The presence of a vasculitis involving capillaries and small arterioles in the lung sections examined makes a hypersensitivity reaction of some kind probable. If this was the result of an exposure to a dust-laden atmosphere, it is likely from the location and distribution of the lesions that an antigen penetrated the mucosal wall of the bronchioles or alveolar duct, and that an antigenantibody reaction occurred which resulted in a vasculitis, disruption of the vessel, neutrophil infiltration of its wall, capillary thromboses, oedema and haemorrhage, and a tissue reaction which involved a mononuclear infiltration with proliferation of the neighbouring alveoli and bronchiolar walls. The disruption of the wall of the bronchiole, usually only a segment of a wall whilst the rest of the wall remained quite uninvolved, is unusual and distinctive, although a peri-bronchiolar lesion was well illustrated by Totten et al. (1958) (Figs 5 and 6). The site of this cellular reaction may well indicate the point of penetration of the wall by the antigen.

Of sensitivity reactions as classified by Gell and Coombs (1963) this is evidently not a type I or anaphylactic reaction, which occurs when antibody is absorbed on to a cell membrane and on subsequent challenge by antigen there is cell injury with the release of histamine-like substances. Nor is a type II reaction likely, for that is typified by the reaction of antibody with tissue cells, and in this case the circumstances of the reaction suggest that one of the two components, antibody or antigen, and doubtless the latter, is of extraneous origin.

Rather does the histological picture suggest that a type III, or Arthus type reaction, has taken place although a concomitant type IV delayed sensitivity reaction cannot be excluded on histological grounds, particularly as the picture of the two reactions in the later stages may be similar (Gell and Hinde, 1954).

Just as some patients with farmer's lung also develop asthma (a type I reaction) on exposure to mouldy hay, so it is possible that in any case of this disease a delayed sensitivity reaction (type IV) of the tuberculin type, which is not dependent on precipitating antibodies, may develop in addition to and alongside the Arthuslike reaction.

Gell and Hinde (1954), Humphrey (1955), and Ovary (1958) all agree that the earliest changes to occur in the Arthus reaction include thrombi, occlusion of severely damaged small vessels, fibrinoid necrosis, haemorrhages, and a perivascular infiltration with neutrophils. Humphrey (1955) was able to demonstrate these changes in rabbits 1-2 hours after injection of antigen. After 12-24 hours the number of neutrophils declined, giving way to infiltration with mononuclears. Necrosis other than capillary necrosis was not a feature of our case but, according to Gell and Hinde (1954), this is not an essential feature of the Arthus. Using graded doses of antigen, lesions could be produced which showed all the histological features of an Arthus reaction but without necrosis.

The lesions observed in this present case closely resemble the experimental lesions described by Gell and Hinde (1954), except that the marked plasma cell proliferation, which they observed at three days, was not seen in our case.

The histology is to be compared and contrasted with that of the tuberculin reaction which was studied in detail by the same authors (Gell and Hinde, 1951). Plasma cells were apparently not seen in the latter reaction, but in the rabbit the two types of lesion at 48-72 hours were remarkably similar both in general pattern and in cell types involved. In the tuberculin reaction cells variously described as histiocytes or reticulum cells were found to be arranged in perivascular accumulations, and to produce a fine reticulin network, two features which were present in our case, but neither at 4 hours nor at 22 hours was any vascular lesion noted in the tuberculin 


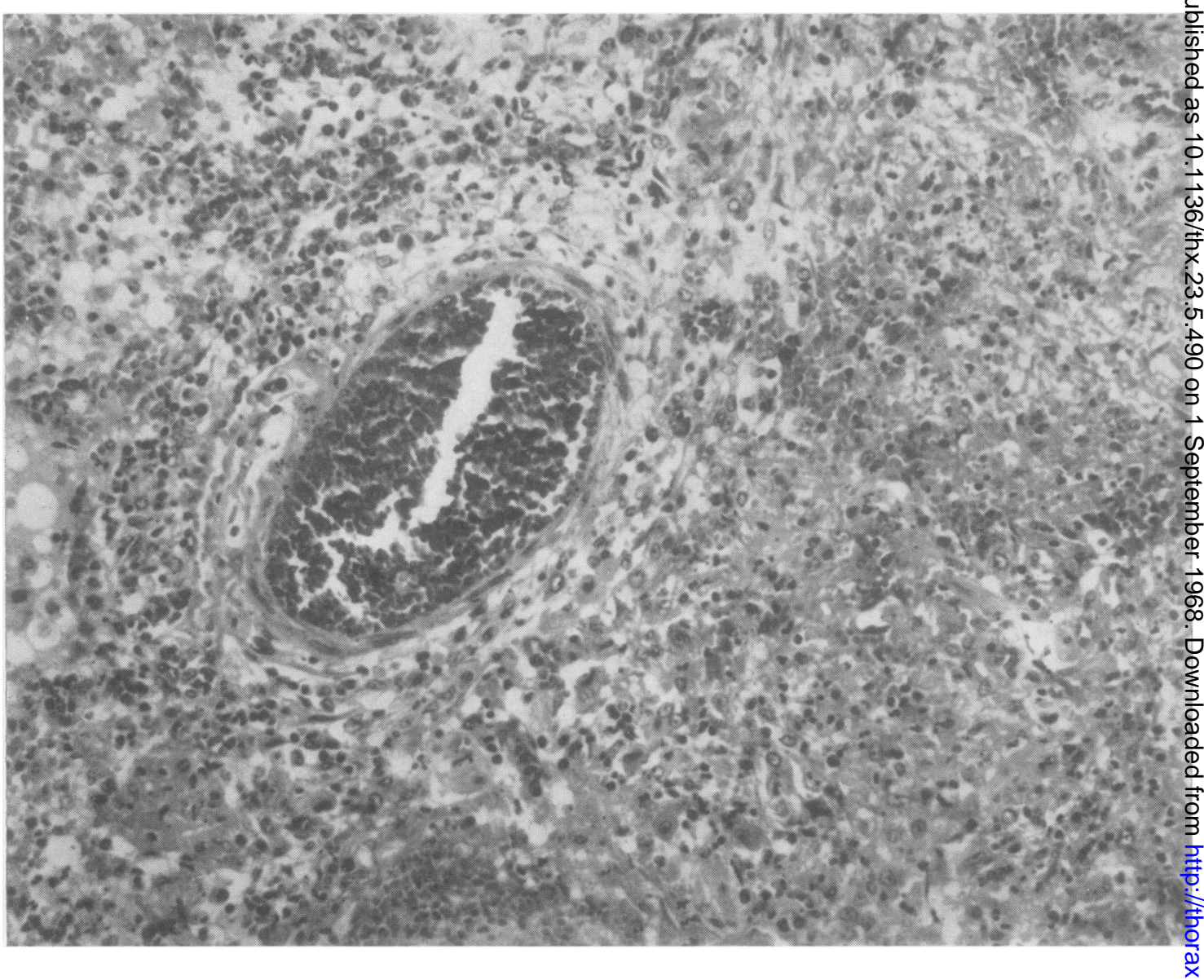

FIG. 9. Lung section of a rabbit which was sensitized to horse serum, showing acute reaction resulting when horse serum was inhaled. $($ H.E. $\times 200$.) (Courtesy of Dr. R. M. E. Seal. $)$

reaction which resembled that seen either by us or by those who have studied Arthus reactions under experimental conditions.

Seal (1966, personal communication) produced an Arthus-type response in the lung of a rabbit sensitized with horse serum. The arteriolitis and interstitial pneumonia which result bear many resemblances to the lesions found in this case. Both show a proliferation of pulmonary alveolar epithelium, considerable reticulin formation, and early giant cell formation in addition to a vasculitis (Fig. 9). However, thrombi, haemorrhages, and acute inflammatory cell infiltration are more evident in the present human case than in his experimentally produced reaction. In artificially induced Arthus reactions of all kinds the recognized time interval between the injection of antigen into the sensitized animal and the occurrence of the typical reaction is about 4-6 hours. The interval between exposure to the dus of mouldy hay and the onset of symptoms irg cases of farmer's lung is commonly of this order If the reaction in this case, or in other cases of farmer's lung, was a little slower in developing than a classical Arthus reaction, the explanatior may lie in the time which might be taken for the challenging antigen to penetrate the mucosa. The solubility of the naturally occurring antigen is not known, and the histology supports the view that it is only when the antigen has penetrated to the submucosa that the violent reaction occurs. The? nearby mucosa is unaffected and quiescent, takingo no part in the reaction.

Williams (1963), using Seitz-filtered extracts ofD mouldy hay to precipitate acute attacks of farmer's lung in sensitized subjects, concluded that the active antigen or agent did not reside ing 


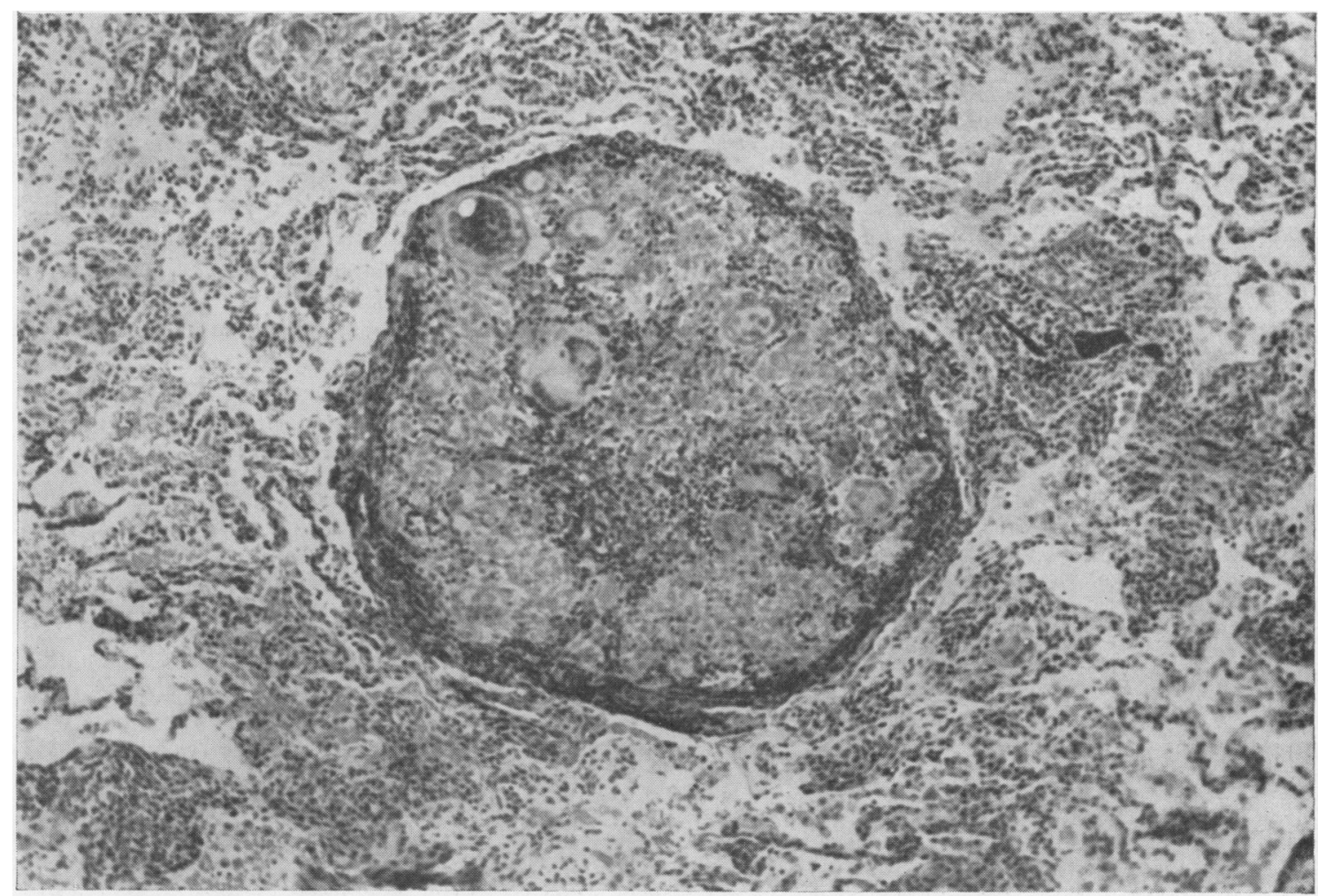

FIG. 10. Section of a sarcoid-like granuloma from a biopsy of lung in a case of farmer's lung of four weeks' duration. (H.E. $\times 100$.) (Courtesy of Dr. R. M. E. Seal.)

particles of less than $20 \mathrm{~m} \mu$ diameter. If confirmed, this would explain why the most prominent lesions in the present case occurred in the bronchiolar-alveolar duct region, the point at which such particles might be arrested.

The nature and the microscopical appearance of any pathological process will always vary with the tissue in which it is occurring. This was emphasized by Hyman and Zeldow (1963) when they noted the variation in the Arthus reactions occurring concurrently in the skin and in the submucosa of guinea-pigs. Necroses of classical Arthus were seen in the skin but not in the submucosa. In this respect the parenchyma of the lung may be comparable with the loose connective tissue of the submucosa.

PROBABLE SUBSEQUENT FATE OF THE LESIONS From the abundant reticulin formation seen in this case fibrosis would be expected in a few weeks' time, and the end result of a fibrotic and perhaps cystic lung could give little or no clue as to the nature of the pathological process which initiated it.

Seal et al. (1963) described the microscopical appearances of a lung biopsy from a case of acute farmer's lung of four weeks' duration. They found sarcoid-like granulomata of epithelioid and giant cells with proliferation of alveolar epithelium (Fig. 10). Totten et al. (1958) reported very similar findings in cases of six months' duration. From the shape and size of the lesions in the present case, and the appearances of the multinucleate cells among the plump proliferating alveolar epithelial cells, their development into such sarcoid-like granulomata would not be unexpected.

At the stage at which it was observed, the pulmonary lesion in this case was quite readily distinguishable from what is known of the histological structure of lesions of comparable age caused by tuberculosis, histoplasmosis, coccidioidomycosis, and blastomycosis, conditions which may cause difficulties in the diagnosis of farmer's lung if seen later in the disease. 
RELATION OF SYMPTOMS TO PATHOLOGY The extreme dyspnoea observed in this and in most other cases of acute farmer's lung is readily explicable by the conspicuous plugging of the bronchioles and alveolar ducts with the mixture of various cells, fibrin, and debris which is invaginated through the wall. Pepys and Jenkins (1965) remarked that the dyspnoea is out of proportion to the radiological changes observed.

The observation of Bishop, Melnick, and Raine (1963) that there is a greatly reduced diffusing capacity with 'alveolar-capillary block' is given a morbid anatomical basis.

Blood-staining of the sputum is explained by the haemorrhages and thromboses caused by the vasculitis.

The vasculitis would certainly account for the severe general symptoms which are frequently observed. These symptoms-fever, malaise, shivering, and loss of weight-are often out of proportion to the physical signs and radiographic changes in the chest.

\section{SUMMARY OF EVIDENCE THAT THE FUNDAMENTAL EARLY LESION INCLUDES A SENSITIVITY REACTION OF THE ARTHUS TYPE}

1. Before an attack of the disease there is always an exposure to mouldy hay, from which antigenic material capable of precipitating an acute attack can be recovered. Antigenic material may also be prepared artificially and used to provoke an attack.

2. In most cases of naturally occurring disease, as well as in those attacks which have been provoked experimentally, the time interval between exposure to antigen and the clinical attack is about six hours, which is comparable with the time taken for an Arthus reaction to develop.

3. Precipitins in the serum are a prerequisite for an Arthus reaction. Precipitin-antibodies have been demonstrated repeatedly in cases of farmer's lung, and, once sensitized, a patient remains liable to repeated attacks for a long period of time. This is a characteristic of Arthus reactions.

4. The histological picture observed in the lung in this early case is entirely in keeping with the histology of Arthus reactions in other parts of the body.

5. The picture also resembles closely that seen in Arthus reactions produced experimentally in the lung of a rabbit.

6. An Arthus reaction is dependent upon the presence of a local excess of antigen over the precipitating antibody. The many litres of air carrying antigenic material which pass through the bronchioles per minute would fulfil those conditions.

7. The involvement of the bronchiolar wall is indicative of an airborne component. The involve= ment of the vascular wall suggests that a blood borne component, probably the precipitating anti body, played a part in the reaction.

8. The fever, chills, malaise, and other clinica features which are observed are what would bê expected if an Arthus reaction were occurring throughout the lung.

9. Arthus reactions are suppressed by corticoe steroids. So, too, are the experimentally produce $\mathbb{P}$ skin lesions in a closely related disease, pigeonfancier's lung, as reported by Hargreave, Pepys Longbottom, and Wraith (1966), and a striking clinical response in cases of acute farmer's lung has been reported by Emanuel et al. (1964).

We are grateful to Drs. I. G. Murray and P. $\mathbf{M}_{\boldsymbol{\varphi}}$ Gregory for serological and mycological examina tions, to Dr. R. M. E. Seal for the loan of Figures 9 and 10 and for serological examinations, and to Dro W. M. Priest, under whose care this patient was admitted to hospital.

\section{REFERENCES}

Bishop, J. M., Melnick, S. C., and Raine, J. (1963). Farmer's lung studies of pulmonary function and aetiology. Quart. J. Med. 32, 257.

Dickie, H. A., and Rankin, J. (1958), Farmer's lung: an acute. granulomatous interstitial pneumonitis occurring in agriculturaf workers. J. Amer. med. Ass., 167, 1069.

Emanuel, D. A., Wenzel, F. J., Bowerman, C. I., and Lawton, B. R (1964). Farmer's lung. Amer. J. Med., 37, 392

Gell, P. G. H., and Coombs, R. R. A. (1963). Clinical Aspects of Immunology. 1st ed., p. 317. Blackwell, Oxford.

- and Hinde, I. T. (1951). The histology of the tuberculin reaction and its modification by cortisone. Brit. J. exp. Path., 32, 516. (1954). Observations on the histology of the Arthus reaction and its relation to other known types of skin hyper? sensitivity. Int. Arch. Allergy, 5, 23.

Hargreave, F. E., Pepys, J., Longbottom, J. L., and Wraith, D. G을 (1966). Bird breeder's (fancier's) lung. Lancet, 1, 445.

Höer, P. W. Horbach, L., and Schweisfurth, R. (1964), Das Krank heitsbild der Farmerlunge und seine Beziehung zu den Pilzinfek tionen. Z. klin. Med., 158, 1 .

Humphrey, J. H. (1955). The mechanism of Arthus reactions. I. Thळ role of polymorphonuclear leucocytes and other factors in reversed passive Arthus reactions in rabbits. Brit. J. exp. Path. N 36, 268.

Hyman, H. M., and Zeldow, B. J. (1963). A comparison of thew cutaneous and mucosal Arthus reaction in the guinea-pig anf hamster. J. Immunol., 91, 701.

Ovary, Z. (1958). Immediate reactions in the skin of experimentab animals provoked by antibody-antigen interaction. Progr. Allergy $5,459$.

Pepys, J., and Jenkins, P. A. (1965). Precipitin (F.L.H.) test in farmer's lung. Thorax, $20,21$.

Seal, R. M. E. (1966). Personal communication. Thomas, G. O., and Griffiths, J. J. (1963). Farmer's lung. Proc roy. Soc. Med., 56, 271.

Totten, R. S., Reid, D. H. S., Davis, H. D., and Moran, T. J. (1958) $\frac{\Omega}{\overparen{D}}$ Farmer's lung. Amer. J. Med., 25, 803.

Williams, J. V. (1963). Inhalation and skin tests with extracts of hayo and fungi in patients with farmer's lung. Thorax, 18, 182 